\title{
What are the limits to the obligations of the
} nurse?

\author{
Steven D Edwards Centre for Philosophy and Health Care, University of Wales, Swansea
}

\begin{abstract}
This paper enquires into the nature and the extent of the obligations of nurses. It is argued that nurses appear to be obliged to undertake supererogatory acts if they take clause one of the United Kingdom Central Council for Nursing, Midwifery and Health Visiting (UKCC) Code of Professional Conduct seriously (as, indeed, they are required to do). In the first part of the paper, the nature of nursing obligations is outlined, and then the groups and individuals to whom nurses have obligations are identified. Following a brief discussion of the moral foundation of the nurse's obligations to her/his employer, a common conflict of obligations is identified. Then a distinction is drawn between ordinary and extraordinary moral standards. Appreciation of this is necessary for an understanding of the criterion of what constitutes a supererogatory act. By the definition of supererogatory acts proposed below, it is suggested that actions such as whistleblowing satisfy that definition.
\end{abstract}

Clause one of the UKCC code ${ }^{1}$ indicates that nurses are under a professional obligation to "... act always in such a way as to promote and safeguard the interests and well-being of patients and clients". However, the extent to which nurses are obliged to act in accordance with this professional obligation may be unclear. For example, suppose that a nurse believes levels of patient care to be below an appropriate level. Suppose further that the nurse acts in accord with clause eleven of the UKCC code and reports to "an appropriate person ... circumstances in the environment of care which could jeopardise standards of care". ${ }^{1}$ Suppose yet further, that having done this, no improvement in standards of patient care ensues.

What should the nurse do? If the nurse takes clause one seriously, it may be claimed that the nurse should then become a "whistleblower" and draw the attention of persons beyond the health care context to the poor levels of patient care. But in so doing the nurse may suffer some harms - both to herself and

\section{Key words}

Nursing ethics; supererogation; whistleblowing. to her dependants. The Department of Health's management executive has stated that breaches of $\mathrm{N}_{\mathrm{N}}$ confidentiality "[Will] always warrant disciplinary iv action". ${ }^{2}$ So a nurse who breached confidentiality in $\varnothing$ order to draw attention to poor levels of patient care would inevitably face disciplinary action even if the breach is justified on moral and professional grounds.

As will be seen, supererogatory acts are acts which go beyond what is obligatory by ordinary moral standards. ${ }^{3}$ It will be shown below that acts such as whistleblowing can plausibly be regarded as supererogatory acts. If nurses are to take clause one of the UKCC code ${ }^{1}$ seriously it would appear to be the case that nurses are under an obligation to undertake acts which are supererogatory - or so it will be argued here.

\section{1: Professional and moral obligations}

A distinction can be made between professional obligations (and duties) and moral obligations (and duties). By entering into the nursing profession nurses take on certain professional obligations. These are stated in the UKCC code $^{1}$ : nurses have obligations to respect confidentiality, the religious beliefs of patients and so on. But in addition to these professional obligations, commentators suggest that nurses are under certain moral obligations. ${ }^{4}$ What is suggested is that nursing is not the kind of occupation which people enter simply for the financial rewards, rather nursing is entered by persons who, by and large, want to help others want to do good. Hence, Seedhouse ${ }^{5}$ claims that work for health is a moral endeavour. This is because it involves striving towards an end which is deemed to constitute a "good"; namely, to improve the health and develop the autonomy of those who are patients and clients.

So nurses are certainly under professional obligations (as set out in the UKCC code) and, if work for health is a moral endeavour (as it can plausibly be regarded), then nurses would seem to be under certain moral obligations. But to whom do nurses have these obligations? At least seven groups and individuals may be identified. 


\section{2: To whom do nurses have obligations?}

(A) OTHER NURSES

Clauses thirteen and fourteen of the UKCC code $^{1}$ indicate that nurses have professional obligations to their fellow nurses. Clause thirteen states that nurses are under an obligation to have regard to the "health and safety" of their colleagues. ${ }^{1}$ And clause fourteen states a professional obligation to help one's colleagues “... to develop their professional competence". ${ }^{1}$

The professional obligation to have regard to the workload of one's colleagues has its moral foundation in the principle of non-maleficence; this principle lays down an obligation not to harm others. ${ }^{6}$ Harm here can be taken to encompass both psychological and physical harm. Hence a nurse who has such an unreasonably heavy workload that he suffers severe psychological stress can be said to endure harms. Also, a nurse who, for similar reasons, finds himself frequently lifting patients in circumstances likely to lead to back injury to himself can be said to be exposed to high risk of physical harm. So obligations of non-maleficence to one's colleagues appear to involve seeking to ensure that their conditions of work are such that they are not likely to be exposed to such high risks of significant harm.

The obligation to help colleagues may plausibly be said to have its moral foundation in the principle of beneficence, according to which one is obliged to act in ways which will benefit or help others. Benefit, here, can be construed as helping others "further their important and legitimate interests" as Beauchamp and Childress put it. ${ }^{7}$ In the nursing context this may plausibly be taken to involve facilitating the development and enhancement of the professional skills of colleagues.

\section{(B) PATIENTS AND THEIR RELATIVES}

Professional obligations to promote the well-being and autonomy of patients and their relatives are indicated in clauses one and five of the UKCC code. ${ }^{1}$ The moral foundations of these professional obligations would seem to lie in the moral principles of beneficence and respect for autonomy.

\section{(C) OTHER HEALTH CARE PROFESSIONALS}

Clause fourteen of the UKCC $\operatorname{code}^{1}$ indicates professional obligations to assist other members of the health care team. Again, it can be said that the moral foundation of this obligation lies in the principle of beneficence.

\section{(D) TO THE GENERAL PUBLIC}

The UKCC code states that nurses are bound by a professional obligation "[To] serve the interests of society [and to] act in such a manner as to justify public trust and confidence". ${ }^{1}$ Presumably this professional obligation has its moral foundation in the principle of beneficence. It is necessary that patients trust nurses so that they will co-operate in treatment regimes and give relevant information to aid diagnosis etc (for example, family history of the relevant disorder).

\section{(E) TO THEMSELVES?}

A question mark has been placed after this due to lack of clarity surrounding what could be meant by such an obligation. Minimally, perhaps it denotes an obligation to be physically and mentally fit enough to perform one's professional duties. Construed in such a way it suggests that this obligation is a purely instrumental one: a nurse is obliged to stay fit and healthy in order that others may benefit from this. Construed differently, it may be held that one owes it to oneself, so to speak, to have a minimally decent standard of living - with sufficient material comforts and so on.

\section{(F) TO THEIR DEPENDANTS}

It is a view widely held among nurses and other moral agents that they have moral obligations to their dependants. Again, the moral foundations of such obligations appear to be the principles of beneficence and non-maleficence. The relevance of beneficence here seems self-evident: one is under an obligation to act in ways which will benefit one's dependants.

With respect to non-maleficence, this states an obligation not to act in ways which will result in harm to others (rather, result in more harm than good). If, say, drawing attention to poor levels of care may result in being unable to provide basic necessities for dependants, it may be concluded by some nurses that they should keep quiet about their concerns. (This issue is returned to shortly.)

\section{(G) TO THEIR EMPLOYERS}

Curtin and Flaherty ${ }^{8}$ suggest that these are two-fold. First, to practise as a competent professional; that is, to practise in accordance with the standards set out by the nurse's professional body. Second, to be involved in the management of the institution to some degree. Curtin and Flaherty ${ }^{8}$ point out that some nurses explicitly have such a role - nurse managers. But other nurses have such a role only implicitly, by their day-to-day decision-making, for example, concerning how best to use resources such as linen, sterile dressings and so on. One might usefully add a third obligation which nurses may plausibly be said to be bound by: namely not to use health care resources wastefully.

It seems reasonable to regard all three of these obligations as professional obligations; but what is their moral foundation?

\section{3: The moral foundation of the nurse's obligations to her employer}

Recall the suggestion referred to earlier - that work for health is a moral endeavour, in that it involves 
working to promote a good, the good of restoring health or fostering the autonomy of patients and clients.

These considerations indicate that the moral foundation of health care work involves at least the principle of beneficence. It is the case that health care should result in good for patients and clients (even if on occasion it does not). Also, the principle of non-maleficence is of central importance. The very least one would expect of work for health is that it does not result in harm to patients and clients. The benefits they obtain should outweigh any harms they may suffer (for example, in undergoing surgery).

So presumably the point of health care institutions is to facilitate work for health; that is, to make possible the conditions under which nurses (and others) can work to benefit others - can carry out the obligations generated by the principle of beneficence.

This suggests that nurses' obligations to their employers and to the institutions in which they work are only legitimate obligations in so far as they contribute to the general aim of making people well.

So although nurses are under an obligation not to squander health care resources, they are not under an obligation to be so frugal with health care resources that patient care suffers. In other words, the obligations nurses have towards their employers should not be permitted to overshadow the more fundamental obligations of nurses; these being directed at patients or clients. This point is worth labouring a little since the overall aim of the nurse's obligations to her employers can be lost sight of. It can seem that (say) being frugal with resources - an obligation to the nurse's employers - can outweigh an obligation to benefit patients. But it should be clear that the obligations to patients are more fundamental, or primary, since the obligations to employers and institutions only exist because of the obligations to patients and clients.

\section{4: Conflicts of obligations}

Nurses frequently point to the adverse consequences of drawing attention to bad practice (the plight of Graham Pink is often cited). ${ }^{9}$ They fear being labelled a trouble-maker, that their career prospects will be harmed ${ }^{10}$ and worse, that they may lose their position. Such nurses may point to a conflict of obligations: obligations to patients and clients on the one hand; and obligations to themselves and their dependants on the other; or some other combination of conflicts of obligation. What ought nurses to do in such situations? In what follows it will be seen that those who claim that nurses are indeed under an obligation to draw attention to poor standards of patient care (namely, those who expect nurses to act in accord with clause one of the UKCC code) expect nurses to undertake actions which qualify as supererogatory. To define properly "supererogatory" it is necessary to outline a distinction between ordinary and extraordinary moral standards.

\section{5: The distinction between ordinary and extraordinary moral standards}

Beauchamp and Childress ${ }^{11}$ suggest that a distinction may be drawn between ordinary and extraordinary moral standards. They indicate that "everyone" 11 is bound by the principles of respect for autonomy, non-maleficence and justice. These principles generate obligations to respect others, not to harm them, and to treat them fairly. Actions done in accordance with these principles constitute acts done in accordance with the standards of ordinary morality. Note that the principles state fairly minimal obligations (not to harm others and so on). The more demanding obligations generated by the principle of beneficence do not appear to feature in ordinary moral standards; it is considered morally acceptable to eat meat, to ignore those who are homeless and hungry, and to ignore the plight of persons in very poor countries. Ordinary morality distinguishes between harming someone by omitting to help them, and harming someone by actively hurting them. The question of whether this distinction is, in the end, morally coherent will not be addressed here. ${ }^{12}$

Even if it is conceded that the obligations generated by the principle of beneficence do feature in ordinary moral standards, it may be pointed out that the extent of the application of this principle is limited. For example, whilst there is a strong obligation not to harm others (by ordinary moral standards), there do appear to be limits to the obligations generated by beneficence. It may be claimed that there is an obligation to act in ways which benefit others - at least other persons. It may be suggested that those persons who ignore homeless and hungry persons are not acting in accordance with ordinary moral standards; suppose this is accepted.

However, by ordinary moral standards the principle of beneficence does not appear to generate an obligation to act in ways which will benefit others if acting in such a way results in significant harm (or deprivation) to the actor. Hence, although it may be argued that by ordinary moral standards one is under an obligation of beneficence to, say, a homeless and hungry person, it is unlikely to be maintained that one is obliged to give to that person even if this entails some suffering to oneself or to one's dependants.

Actions which are done in accordance with extraordinary moral standards are termed "supererogatory" by Beauchamp and Childress; such acts "... are undertaken for the welfare of others beyond what obligation requires". ${ }^{13}$ That is to say, such acts exceed what is obligatory by ordinary moral standards. 
One substantial difficulty with the distinction between ordinary and extraordinary moral standards is that extraordinary moral standards will be defined only relative to ordinary moral standards. Obviously, if ordinary moral standards were more morally demanding, then what would be regarded as extraordinary would be different. For example, suppose it is obligatory by ordinary moral standards to give away all one's possessions (except those essential for survival) for the benefit of others - say persons in extremely poor parts of the world. Presumably, acting in accordance with extraordinary moral standards would then involve giving away all one's possessions for the benefit of others - even those possessions necessary for one's continued survival. I do not propose to pursue the difficulty just mentioned. It is plausible to claim that, at present, such actions are not regarded as obligatory by ordinary moral standards. The discussion engaged in here is in the context of presently accepted moral standards and not hypothetically more demanding future standards.

So let us set aside this difficulty and accept the distinction between ordinary and extraordinary moral standards as set out above. A person who acted in a way which was for the good of another person but which resulted in harm to herself or her dependants could plausibly be described as acting in accordance with extraordinary moral standards. By ordinary moral standards such actions do not seem to be morally obligatory.

Recall now the definition of supererogatory actions offered above. These are: “... undertaken for the welfare of others beyond what obligation requires"." The expression "what obligation requires" can be taken to mean "what is obligatory by ordinary moral standards".

\section{6: Conflicts of obligation again}

Consider now the nurses referred to earlier; they pointed to the adverse consequences of speaking out about low levels of patient care or malpractice. Having exhausted all "internal" means of changing the situation, the nurse must consider just which course of action to take. Acts such as whistleblowing are acknowledged by nurses to be for the good of patients but are feared because they might have adverse consequences for the nurse concerned; such acts do not seem to be obligatory by ordinary moral standards (since, by these one is obliged to do good only if it does not result in harm to oneself or one's dependants). So acts such as whistleblowing would appear to meet the definition of supererogatory acts defined above - they are for the welfare of others but go beyond what is obligatory by ordinary moral standards.

It should be inferred, then, that a nurse is not under an obligation by ordinary moral standards to draw attention to low levels of patient care if in so doing the nurse runs a high risk of harming herself or her dependants.

Should nurses be expected to take on the standards of extraordinary morality, and so perform acts which are supererogatory? Clause one of the UKCC code seems to suggest that they should, since it obliges nurses to place obligations to promote the well-being of patients above other obligations. I do not propose to pursue in depth the question of whether nurses are obliged to undertake supererogatory actions, but the following concluding remarks seem relevant

\section{7: Concluding remarks}

First, it should be pointed out that in questions of whistleblowing what are being balanced against each other are (a) actual harms presently being undergone by patients versus (b) possible harms to the nurse and her dependants. The Department of Health document referred to earlier is explicit that nurses who do blow the whistle can expect disciplinary action, ${ }^{2}$ but it is not clear what this will amount to. So it is not possible to determine the degree of harm which will befall the nurse. Also, it is plausible to hold that actual harms undergone count for more than harms in the kind of calculation just envisaged.

Second, the point may be made that nursing is the kind of occupation which is essentially concerned with promoting well-being. So it can be claimed that it is part of a nurse's station, so to speak, and the duties which accompany the taking up of such a station, to place the well-being of patients and clients especially highly in the ordering of her moral priorities. So in the event of a conflict of obligations the obligations to patients and clients would win out. The latter position is one according to which nurses have an obligation to act in accordance with extraordinary moral standards and so be prepared to undertake supererogatory actions - at least whilst they are on duty. A position close to this seems to be favoured by Gillon; in commenting upon the extent of the obligations of doctors he states "doctors have a moral duty to benefit their patients over and above any general duty that may exist for us all to benefit each other, or for us all to benefit the sick". ${ }^{14}$ However, it seems to me that the more pressing question concerns the extent to which nurses (and doctors) are bound by the obligations to benefit others referred to by Gillon. For example, are nurses obliged to act in ways which benefit patients even if this leads to substantial harms to themselves and their dependants? It is evident that a nurse who blows the whistle over concerns about standards of care is likely to suffer intense psychological stress, may lose her position, and may not be able to meet quite basic obligations to her dependants (if, for instance, she loses her professional position). If nurses are being expected to make such decisions, it 
seems plausible to regard whistleblowing as a supererogatory act.

In short, the problem for nursing staff seems to be this: the UKCC code appears to state that obligations to patients and clients outweigh other competing obligations. If attempting to fulfil this position carries the likely consequence that one will be disciplined or lose one's position, is the nurse obliged to take whatever courses of action will improve patient care, or should the nurse merely exhaust all internal means of bringing about change? If the nurse rests with the second option and low levels of patient care persist, the nurse is presumably practising in contravention of her own code of professional conduct and is, hence, open to censure. There is clearly a deep problem here from both moral and professional perspectives but it is beyond the scope of this paper to offer a solution. My purpose has merely been to set out the problem.

In conclusion, it may be said that nurses who refrain from whistle-blowing due to fear of possible harms to themselves and their dependants are acting in accordance with ordinary moral standards; those who do not so refrain, perform acts which are supererogatory. Clause one of the UKCC code thus appears to require nurses to act in ways which qualify as supererogatory as that term has been defined here.
Steven D Edwards is Lecturer in Health Care Ethics in the Centre for Philosophy and Health Care, University of Wales, Swansea.

\section{References and notes}

1 UKCC. UKCC code of professional conduct [3rd ed]. London: UKCC, 1992.

2 Department of Health. Guidance for staff on relations with the public and the media. London: DOH, 1993.

3 Beauchamp TL, Childress JF. Principles of biomedical ethics. Oxford: Oxford University Press, 1989. For the sake of argument, I merely presume the acceptability of the principle-based line in the paper.

4 For example, Melia K. Everyday ethics for nurses. London: MacMillan, 1989.

5 Seedhouse D. Ethics: the heart of health care. Chichester: Wiley, 1988: xvii.

6 See reference 3: 120 .

7 See reference 3: 194.

8 Curtin L, Flaherty MJ. Nursing ethics: theories and pragmatics. London: Prentice Hall, 1982: 154.

9 Hunt G. Whistleblowing in the health service. London: Edward Arnold, 1995.

10 Brindle D. Whistleblow warning in health charter. The Guardian 1992 Oct 17: 2.

11 See reference 3: 366-7.

12 Glover J. Causing death and saving lives. Harmondsworth: Penguin, 1977.

13 See reference 11: 367.

14 Gillon R. More on professional ethics. Fournal of Medical Ethics 1986; 12: 59-60.

\section{News and notes}

\section{The Annual Intensive Course on Medical Ethics 16-20 September, 1996 at Imperial College, London}

The course provides a multidisciplinary introduction to philosophical medical ethics for medical and nursing teachers, medical practitioners, members of ethics committees and medical administrators. It is organised in collaboration with the Institute of Medical Ethics, and directed by Professor Raanan Gillon, Editor of the Fournal of Medical Ethics and Professor of Medical Ethics of the Imperial College Analytic Ethics Unit. The course consists of lectures/seminars, and small and large groups led by leading international authori- ties in the field of medical ethics. Participant ratings over the last ten years have consistently given an overall course rating of better than 9 out of 10 satisfaction.

PGEA and CME approval sought for 1996.

For further details, please contact: Sally Verkaik, The Continuing Education Centre, Imperial College, Room 558 Sherfield Building, London SW7 2AZ. Tel: +UK (0)171 594 6881/2. Fax: +UK (0)171 594 6883, E-mail: $\operatorname{cpd}(\omega$ ic.ac.uk. 